algo más diluidos en un ambiente más oscuro. La utilización de la luz, unida a una concepción monumental de las figuras, dota a las mismas de unos valores claramente escultóricos, sumamente característicos de la época. La gama cromática empleada destaca por la utilización de azules, rojos y rosas, estos últimos de ascendencia tardomanierista.

El lienzo burgalés, custodiado en el Museo de Burgos, es también una pintura sobre óleo que presenta casi las mismas dimensiones que el romano $(240 \times 175 \mathrm{cms}$.). Como ya señalamos, anteriormente, esta pintura estuvo ubicada en el Monasterio de San Salvador de Oña hasta que pasó a formar parte de los fondos de este museo tras la Desamortización. Desconocemos cómo se produjo la llegada de esta pieza a este centro monástico ${ }^{10}$. Sin duda, la importancia que tuvo el monasterio a lo largo de la Historia le facilitó la adquisición de piezas no sólo de maestros españoles sino también foráneos ${ }^{11}$. Quizá la llegada de este lienzo a Oña estuvo en relación con la de alguna reliquia de santa Prisca. Hemos de recordar que en los últimos años del siglo xvi y en el siglo xvir el tráfico de reliquias en el mundo católico vivió un notable resurgimiento, a raíz de los favorables dictámenes trentinos a su culto, sobre todo de aquéllas vinculadas a santos y santas de los primeros momentos del cristianismo.

Creemos que esta obra salió del propio taller del Passignano y que probablemente se realizó o bien por el propio maestro o por algún oficial destacado en el mismo. La calidad es sumamente pareja en el cuadro romano y en el burgalés. La definición del dibujo, el tratamiento de los rostros y manos, el de los paños y la disposición de todos los elementos resultan semejantes. Las únicas diferencias sustanciales que existen entre ambas pinturas las hallamos en la forma de realizar el rompimiento de cielo y en las tonalidades que en el caso de la obra de Burgos resultan ligeramente más apagadas aunque la gama cromática, en ambos lienzos, es la misma, lo que nos ratifica en la idea de que nos encontramos ante una obra salida del mismo ámbito que la romana.

René Jesús Payo Hernanz Universidad de Burgos

\title{
UN RETRATO DE AGUSTÍN ESTEBAN COLLANTES, MINISTRO DE FOMENTO, POR JUSTO MARÍA DE VELASCO Y GALAMINO
}

Dentro del convento de San Francisco de Palencia ${ }^{1}$, en unas dependencias anejas a lo que fue la sede de la Sociedad Económica, arrinconado, se encuentra un lienzo sin firmar (115 $\times$ $87 \mathrm{~cm}$.), en buen estado (apenas una rotura y suciedad), que desde 1887 lució en el salón de actos de la ilustrada corporación. Y es que en aquella fecha, cumpliendo con una de las mandas testamentarias de Justo María de Velasco, el pintor entrega a los Amigos del País un retrato de Esteban Collantes ${ }^{2}$.

\footnotetext{
${ }^{10}$ La primera mitad del siglo XVII es una época de gran dinamismo constructivo y de renovación de los bienes muebles en este importante centro monástico. La importancia del monasterio, panteón real, sin duda, posibilitó no sólo los contactos del mismo con la Corte sino también con Roma de donde, sin duda, procede la pintura.

11 Herrera Oria, Enrique: Oña y su Real Monasterio hoy Colegio de Padres Jesuitas según la descripción inédita del monje de Oña fray Í̃igo de Barreda, Madrid, 1917.

1 Agradezco a doña Ana Isabel Barreda haberme confiado su existencia, así como también al padre Semprún la amabilidad con la que me facilitó el acceso y estudio del cuadro.

${ }^{2}$ El Diario Palentino (10-X-1887) y Archivo Histórico Provincial de Palencia. Sección Protocolos, legs. 16.732, 16.737 y 16.964 (signaturas antiguas).
} 
Justo María de Velasco y Galamino (Salamanca, 1810-Palencia, 1887) era hijo de un acreditado maestro relojero y nieto de una familia de plateros palentinos de nombre Espetillo. Tras un fugaz aprendizaje en la Academia de San Eloy de Salamanca, estudió en Madrid con Vicente López. A los 19 años figura ya como profesor de dibujo. Con 26 es nombrado académico de mérito de San Fernando. En 1839, la Sociedad Económica de Palencia le distingue con la categoría de miembro honorario. Dos años después, la academia fernandina incluye su apellido entre los de los supernumerarios. Asimismo, perteneció a las Academias de San Carlos de Valencia y de San Luis de Zaragoza en calidad de correspondiente. En 1841 se establece definitivamente en Palencia para dirigir la Cátedra de Dibujo de la Sociedad Económica. (Por sus aulas pasará Casado del Alisal, Martínez del Rincón y Mañanós). Socio del Liceo de Madrid y el Ateneo de Palencia, formó parte de la Comisión de Monumentos de la provincia de Palencia y participó con éxito en exposiciones provinciales y nacionales ${ }^{3}$.

El rápido reconocimiento de la obra de De Velasco, además de por la vía de las exposiciones, provino de su dedicación al género del retrato, con una indudable capacidad y conocimiento de los dictados académicos.

El retrato de Esteban Collantes está concebido como un retrato oficial, acaso realizado por encargo directo del Ministerio de Fomento para su galería de retratos, tal vez reponda al encargo de una pintura que hace al Ayuntamiento de Palencia en 1854 por 1.500 reales para su sala de Sesiones. Representado de medio cuerpo, en pie y con rostro de fisonomía agradable, mira distante y confiado al espectador. En apenas un tablero de una mesa sencilla y ligeramente avanzada apoya su mano izquierda en una pose convencional sobre un vade con algunos papeles distraídos en que se lee, dentro de una composición algo aparatosa: «Reales ordenes espedidas por el Escmo. Sr. Ministro de Fomento D. Agustin Esteban Collantes; relativa á las Carreteras de Palencia y León / Real Orden de 31 de Agosto de 1853 de una / Carretera desde Palencia á L[eón] / Otra id. id. id. paa una Carrete[ra] / de Benavente por Palencia. Otra id Morovan / “ “ /

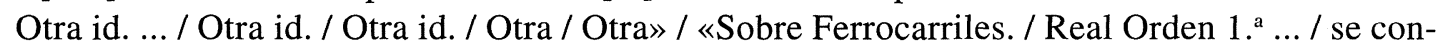
cede / ferrocarri[1] / Castilla / concediendo el ferrocarril de Alar á / Valladolid por Carrión / 2. ${ }^{a}$ ... $\mathrm{R}^{1}$ Orden de 31 de Octubre de 1853; ferroca- / rril desde Valladolid á Burgos pr. Palencia».

Con una técnica de pincel menudo insiste en la descripción del traje y sus condecoraciones: los entorchados y puños de encaje, el forro del faldón derecho de la casaca, las labores ondeadas del muaré de la banda de la Orden de Carlos III, los brillos metálicos de la placa gran cruz correspondiente, junto a las condecoraciones de la Legión de Honor, la placa de gran Oficial de la Orden de Cristo y la Cruz de las Epidemias. La vista de la venera que cierra la banda, en cambio, aparece demasiado forzada.

Un sencillo interior de salón fija la composición. El perfil de un marco sugerido a la izquierda y la inscripción mural en la mitad inferior derecha refuerzan la idea de su adscripción a una colección abierta en lo que podría ser un pequeño juego: definir el lienzo de pared que iba a contener en un futuro el retrato y la ilusión de que el ministro estaba posando en la galería de retratos.

Con letras capitales, el protagonista queda plenamente identificado: «EL ESCMO - E ILMO • S • D • AGUSTIN ESTE- / BAN COLLANTES • NACIO EN CARRION DE / LOS CONDES A 13 DE MAYO DE 1815 - DIPUTADO A CORTES / POR LA PROVINCIA DE PALENCIA EN 1844 • REELEGI / DO CINCO VECES POR EL DISTRITO DE CARRION - MINISTRO DE FOMENTO EN $1^{\circ}$ DE AGOSTO DE 1853 / Y DOS VECES INTERINO DE MARINA EN 9 DE SETI- / EMBRE DE 1853 • Y 19 DE OCTUBRE DEL MISMO AÑO».

\footnotetext{
${ }^{3}$ De la colección de apuntes inéditos de historia y arte de Palencia escritos por Ricardo Becerro de Bengoa, la breve biografía de Ossorio y Bernard en su galería de artistas españoles y de pequeñas referencias en mi trabajo sobre la Sociedad Económica de Amigos del País de Palencia.
} 


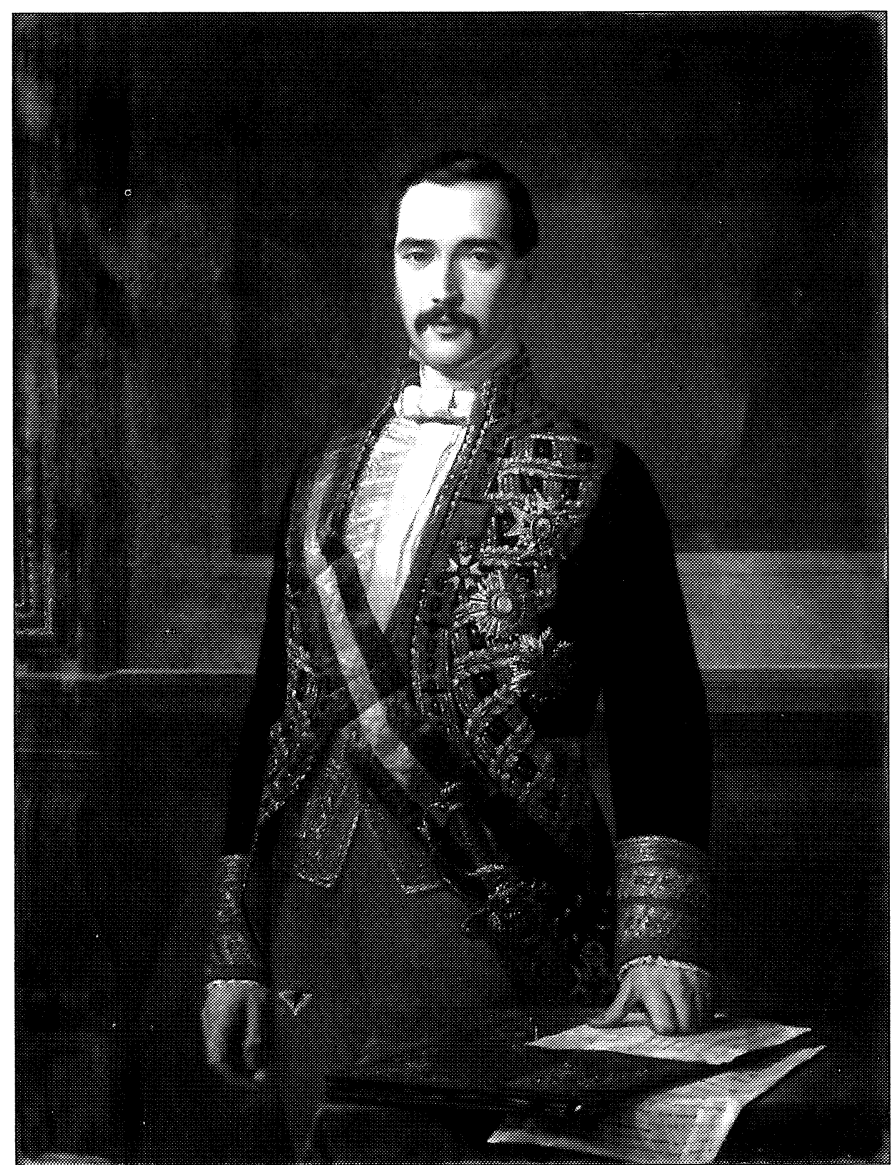

Agustín Esteban Collantes, ministro de Fomento, por Justo María de Velasco (c. 1854).

La datación del cuadro puede ajustarse a partir de la fecha de concesión de la Orden de Carlos III (1854) y el final de su mandato ministerial. Ahora bien, asalta la curiosa particularidad de que las demás condecoraciones (la Cruz de las Epidemias es anterior a la concesión de la de Carlos III), en concreto la lusa, son muy posteriores, por lo que no se hace difícil pensar que fueran añadidas con escrupuloso cuidado de la mano de Justo María de Velasco.

José Luis SÁNCHEZ GARCía

\section{ALGUNOS DATOS SOBRE EL PALACIO ESPAÑA EN ROMA Y EL PATRONAZGO DEL CONDE DE ALTAMIRA EN SU EMBAJADA}

En 1695 Don Luis de la Cerda y Aragón, Duque de Medinaceli, se veía obligado a abandonar su residencia en el palacio romano de la Plaza de España debido al estado de ruina causado por el desplome de gran parte del edificio.

El palacio, que nunca gozó de buena salud, fue objeto de nuevos reparos desde su adquisición para ejercer de sede de la Embajada española en tiempos del Conde de Oñate. Como que- 